\title{
The historical present in Spanish and semantic/pragmatic structure
}

\author{
Carlos Benavides \\ University of Massachusetts Dartmouth
}

The historical present (HP) is the use of the present tense to refer to past events, usually as part of a narrative. Most work on this topic has dealt with the functions of English HP, mainly within the context of tense switching in conversational narrative. Relatively little work focuses exclusively on HP in Spanish, and most of it deals with the function of HP in conversational narratives. There is a gap in the literature regarding the specific interaction between the semantics and pragmatics involved in the use of HP, especially with respect to the formal representation of this interaction. In order to fill this gap, this paper analyzes the use of HP within the Parallel Architecture framework (Jackendoff 2002) and examines the implications for the semantic/pragmatic structure. Language samples produced by native speakers of Spanish and data from a large Spanish corpus are used as part of the basis for analysis. The present study also explores how the use of the preterite and imperfect in narrative in the past parallels the use of the simple present and the present progressive in narrative within the present timeframe, and shows how this can also be fruitfully analyzed employing the Parallel Architecture. The result is an original model that extends the formal apparatus of the Parallel Architecture to an area where it has not been applied before, the interface between semantics and narrative structure.

Keywords: historical present, conversation, narrative structure, discourse, tense switching, tense shifting, corpus data, semantics/pragmatics interface, Parallel Architecture, tier structure

\section{Introduction}

The historical present (henceforth HP), also known as narrative present or dramatic present, is the use of verbs in the present tense to refer to past events, usually in a conversation or as part of a narrative. Most work on this topic has dealt with the functions of HP and the conditions under which it occurs, mainly 
within the context of tense switching in conversational narrative. The vast majority of this work is on English HP (cf. Wolfson 1979; Schiffrin 1981; Fludernik 1991). Only a few articles (and no books) have been published that focus exclusively on HP in Spanish in the last three decades since Van Ess-Dykema's (1984) dissertation, and most of these, as is the case for English, deal with the function and use of HP in conversational narratives. Even though the relationship between HP and narrative structure has been explored, there is a gap in the literature regarding the specific interaction between the semantics and pragmatics involved in the use of HP, especially with respect to the formal representation of this interaction. To help filling this gap, this paper analyzes the use of HP within the Parallel Architecture framework (Jackendoff 2002) and examines the implications for the semantic/pragmatic structure.

Language samples produced by native speakers of Spanish are used as part of the basis for analysis. The samples were retrieved from the Corpus del Español (Davies 2002-) in order to find naturally occurring instances of the use of HP with a set of achievement verbs (e.g. llegar 'arrive') - the event type with which HP occurs the most. Data gathered from conversational narratives by Bonilla (2011) are also considered. Examples taken from oral and written registers in the corpus are used to make comparisons between aspects of oral HP and written HP. The present study also explores how the use of the preterite and imperfect in narrative in the past parallels the use of the simple present and the present progressive in narrative within the present timeframe (see Mayberry 2011), and shows how this can also be fruitfully analyzed employing the Parallel Architecture.

Since the Parallel Architecture is based in large part on Conceptual Semantics (Jackendoff 1990), a framework for semantic analysis, the model proposed here represents the application of a formal technique used in semantics to a phenomenon at the semantics-pragmatics interface. The result is an original model that extends the formal apparatus of the Parallel Architecture to an area where it has not been applied before, the interface between semantics and narrative structure. Thus, the present study points the way for further theoretical development of the interaction between semantic and pragmatic structures.

\section{Previous studies}

HP occurs as a result of tense shifting (or tense switching) between the present and past tense (more specifically, the preterite), usually in narrative. There has been some debate regarding the conditions under which HP occurs and, more importantly, its function. Traditionally, HP has been considered a dramatic device used to make events appear to the listener as if they were happening at the 
moment the story is being told. However, according to Wolfson (1979), it is the alternation between HP and the past tense that is significant, not HP in itself. This alternation functions as a mechanism that separates events in the narrative from one another, rather than making the events in the story more vivid or dramatic.

However, Silva-Corvalán (1983) found that the function of HP in Spanish is not that of separating events, but rather to serve as an internal evaluation mechanism. Evaluation is the means by which a narrator makes a story interesting, highlighting the relative importance of the narrative events (Silva-Corvalán 1983). When this evaluation is done from within the story, it is considered an internal evaluation (cf. Schiffrin 1981). As such, HP is used in the complicating action part of the story to set off the most climactic events from the rest of the narrative; these are also events that highlight the point of the story. HP is used to present past events as if they were occurring at the moment of speaking, right before our eyes, which creates an effect of immediacy and therefore has the expressive function of making past events more vivid and dramatic (Silva-Corvalán 1983). This confirms the use of HP as an internal evaluation device, supporting Schiffrin's (1981) results for English. ${ }^{1}$

Van Ess-Dykema (1984) agrees that the function of HP is to present particular events as appearing to occur before our eyes, making the events feel more vivid and immediate to the listener. This immediacy in turn is related to the high degree of involvement in the story on the part of the speaker (Fludernik 1991). Van Ess-Dykema found that use of HP marks scary, unfortunate, strange, uncommon, unusual, or funny events, which coincides in part with other kinds of events marked by HP. For example, Silva-Corvalán (1983) notes that dangerous, wonderful, weird, or amusing events (taken from Labov 1972) exhibit use of HP, and Fludernik (1991) posits that HP marks surprising, unexpected and emotionally memorable turns of events. The immediacy manifested in spoken narratives can be contrasted to the distance that characterizes some written narratives. As Lubbers-Quesada (2004) notes, on the basis of a study with first- and second-year university students (native speakers of Mexican Spanish), the fact that HP is practically nonexistent in narratives written by the students "reflects the nature of the written narrative as a conceptually distancing task between the events narrated and the narration itself." (See more on written narrative in $₫$ 3.)

1. Responding to Schiffrin (1981), Wolfson (1982) holds that underlying the discussion of the HP-Preterite alternation there has been a basic misunderstanding of the meaning of the term event as she uses it. To Schiffrin (1981), an event is a minimal unit of action, whereas for Wolfson (1979) an event is a grouping of a sequence of acts into a larger unit, which she also calls an episode. 
As seen above, HP is associated with the complicating action (Schiffrin 1981; Silva-Corvalán 1983), the part of the story where the sequence of events is narrated (Labov 1972). In other words, these events occur in the foreground, the part of the narrative which moves the action forward (Hopper 1979). As Bonilla (2011) notes, telic verbs typically occur in the foreground, while atelic verbs are usually associated with the background (description of or comment on situations; cf. Hopper and Thompson 1980). HP occurs more frequently with achievement verbs (cf. Van Ess-Dykema 1984), which are telic, and therefore HP occurs more frequently with the foreground.

Bonilla cites Dunn's (1998) suggestion that past time reference is more readily recuperated in the foreground (by HP) since the background may refer to a greater variety of time reference compared to the foreground. For example, the present tense can be used in the background for general truths and for generalizations that are true in the present; the past perfect for events that happened prior to the time of the story (cf. Bardovi-Harlig 1998); and, in Spanish, the imperfect is used to describe habitual or ongoing actions in the past and to provide other background information, such as descriptions of things, places or characters, and time of day. Thus, HP is more readily interchangeable with a past form in the foreground than in the background, where time reference is more variable. Fludernik (1991) emphasizes that HP is not mere foregrounding, and agrees with Schiffrin (1981) and Silva-Corvalán (1983) that HP guides the listener's evaluation of the events and marks the point of the story, in addition to the peak or climax of an episode. HP signals a narrative "turn" of events.

As another possible function of HP, Bonilla (2011) proposes that HP is used as a way to maintain the conversational turn or to maintain the attention of the participants in the conversation, while the preterite functions to maintain the reference to the past. For example, when an interlocutor interrupts while the speaker is narrating the complicating action in HP, and the speaker responds, the speaker resumes the story with the preterite to maintain the reference to the past, as in the dialogue in (1).

(1) A: ...Y me dice [HP]: 'Echale crómer'...

[... And he tells [HP] me: 'Put some chromer on it'...]

B: ¿Crómer?

[Chromer?]

A: ‘¡Pero usted está loco!... 'Y me dice [HP]: 'Hombre, no sé; eso te lo secaría.' ['But you are crazy!...' And he tells [HP] me: 'Man, I don't know; that would dry it out.']

B: ¿Crómer es mercromina?

[Chromer is mercurochrome?] 
A: Claro.

[Of course.]

B: ¡Ah!

A: Mercromina. El dijo [PRT] 'crómer'.

[Mercurochrome. He said [PRET] 'chromer'.]

B: Sí.

[Yes.]

A: Y entonces le digo [HP] yo: ‘ ¿Pero cómo voy a echar eso?’...

[So then I tell [HP] him: 'But how am I going to put some of that on?']

Making a connection between HP in Latin American Spanish and sociolinguistics, Dyvik (2004) classified HP into five subcategories, as follows: (1) anecdotal HP, to relate personal anecdotes based on first-hand experience; (2) narrative HP, where what is narrated is more general and rarely includes first-hand experiences; (3) HP of saying or speaking, which uses decir 'to say' and similar verbs to introduce direct speech (as in Example 1 above); (4) HP with verbs triggered by verbs of saying; and (5) indeterminate HP, whose status as HP or the typical simple present is not clear. Dyvik examined the interaction between these subcategories and two sociolinguistic variables (educational level and gender), and found marked differences in the frequency of use of some of the HP subtypes in both sociolinguistic groups. For example, less educated speakers tended to make more frequent use of the HP of saying (e.g. Y me dice: “¿Y fuiste?” 'And she tells me: "And did you go?”), while men used the anecdotal HP more frequently than women (within the less educated group) (e.g. ... un día me presenta ... '... one day he introduces me ...') (examples from Dyvik 2004).

Bonilla (2011) conducted two studies with the goal of determining what linguistic factors govern tense shifting in Spanish HP. More specifically, the studies analyzed the patterning of HP with lexical aspectual class, first- vs. third- person usage, and with the verb decir 'to say'. In Study 1, Bonilla (2011) found the following regarding HP: that it mainly occurs in the complicating action of narratives; is overall more frequent than the preterite; patterns more frequently with achievements; and shows a tendency to pattern with third person (when decir was excluded) (the data were taken from the Corpus oral de referencia de la lengua española contemporánea (Marcos Marín 1992); all participants were native speakers of Peninsular Spanish.) The dialogue shown in (1) above is a conversational excerpt from Study 1 (adapted from Bonilla 2011). Bonilla's (2011) corpus data and results serve, in part, as the basis for the analysis in $\$ 5$. The model developed in that section applies precisely to examples of HP such as those in (1).

Bonilla's (2011) Study 2 involved HP use in oral story-retell tasks based on a film segment completed by five native speakers (the data were taken from learner 
and native speaker corpora (SPLLOC 2009) transcribed in the CHILDES database; MacWhinney 2000). Narration occurred almost exclusively in the present tense. Since this task was not strictly conversational, I have labeled it as RHP for Retell Historical Present. Sebastián and Slobin (1994) analyzed a similar type of narrative task, but based on pictures rather than film, where both children and adult speakers told a story depicted in a wordless picture book. As in the RHP, adult speakers in Sebastián and Slobin's (1994) study preferred to narrate almost exclusively in the present tense. Since there is little or no tense shifting in this type of narrative activity, RHP is not pertinent to the analysis in $₫ 5$.

An overview has been presented above of the issues associated to the function of HP. However, the aim of the present study is neither to examine the functions of HP nor to determine the conditions under which it occurs. Rather, as mentioned in the introduction, the goal is to explore the interaction between semantics and pragmatics involved in the use of HP. More specifically, to examine how the semantics of the verbs involved in HP interact with narrative structure, which is a part of discourse and therefore of pragmatics. For this purpose, some of the terminology discussed above pertaining to narrative, such as foreground and background, immediacy and distance, will be relevant for the representations proposed to account for this interaction $\left(\$_{5}\right)$.

Regarding narrative carried out exclusively in the present timeframe, Mayberry (2011) conducted a study aimed at examining the aspectual differences between the usage of simple present and present progressive forms in Spanish in the context of synchronous narratives. Native Spanish speakers viewed a series of videoclips and described the scenes as they viewed them. As Bonilla (2011), Mayberry found that tense selection (in synchronous narratives) is influenced by the interaction between the lexical aspect of the verbal predicates involved and the discourse elements of foregrounding and backgrounding. The use of the simple present and the present progressive in narrative within the present timeframe was found to parallel the use of the preterite and imperfect in narrative in the past, respectively. More specifically, the simple present serves to focus on the telic and punctual features of achievements, in opposition to the ongoingness of the progressive, in a manner that is analogous to the preterite/imperfect aspectual contrast in past narratives.

Thus, while the progressive emphasizes durative and atelic aspectual features and serves to provide the background of the narrative in the present timeframe (just as the imperfect does in the past timeframe), the simple present is used to foreground the telic and punctual events of the main story line (the same role of the preterite in the past time context). The simple present is the only tense in the present time frame that can offer an aspectual contrast in order to move the 
story forward (Mayberry 2011). These findings are relevant for the analysis in $\$ 5.2$, which is based in part on data from Mayberry's study.

The examples in (2) and (3) illustrate the parallels discussed above between past narrative and present synchronous narrative (adapted from Mayberry 2011).

(2) Past narrative

Anoche, aunque me sentía [IMP] cansada leí [PRT] el periódico un rato, cené [PRT] a las siete, y no me acosté [PRT] sino hasta las diez.

[Last night, although I was feeling [IMP] tired I read [PRET] the newspaper for a while, I had dinner [PRET] at seven, and I did not go to bed [PRET] until ten.]

(3) Present synchronous narrative

Una mujer está ordenando [PROG] un sillón, recoge [PRES] unos papeles, y los mete [PRES] en una carpeta, arregla [PRES] la alfombra, guarda [PRES] la carpeta en un baúl, cierra [PRES] el baúl.

[A women is clearing up [PROG] an armchair, she picks up [PRES] some papers, and she puts [PRES] them in a folder, she straightens up [PRES] the carpet, puts [PRES] the folder in a chest, closes [PRES] the chest.]

Notice that the place where the imperfect is used in (2) (sentía 'felt') corresponds to the location in (3) where the present progressive is used (está ordenando is putting in order'), while the preterite, which is used in (2) to narrate a sequence of actions (leí 'I read', cené 'I had dinner' ...), is mirrored by the simple present in (3) for the same purpose (recoge 'she picks up', mete 'puts in' ...).

Finally, it is important to discuss Neil Cohn's work on visual narrative structure, in particular Cohn (2013, 2014a, b), given that these studies are based in part on the Parallel Architecture. According to Cohn (2013), visual narrative structure is the structure of narratives consisting of sequential images. This structure, according to Cohn's $(2013,2014 a, b)$ representations, is composed of narrative categories such as peak (or climax) and release (or resolution) that pertain strictly to the plot (labeled $A r c$ ), but does not incorporate other elements of narrative such as foreground and background, which, as seen above and in $\$ 5$, are an important part of the present study. In addition, even though Cohn's framework can be applied to verbal discourse, it is not directly relevant to the current study, which deals specifically with verbs, not with entire narratives, and, as mentioned above, seeks to address the formal relationship between semantics and pragmatics. Furthermore, as seen in $\$ 5$, the present study focuses on notions such as Conceptual Structure, Grammatical Aspect, and Narrative Distance, not on narrative structure in general, and less so on the narrative categories employed by Cohn.

While Cohn's (2013, 2014a, b) studies are based to some degree on the Parallel Architecture, in Cohn (2013, 2014a) there is no mention or use of tiers, which, 
as shown in $\$ 4$ and $\$ 5$, are key to the current paper. Cohn (2014b) does make use of tiers, but they are of a kind that has no equivalent to the tiers employed in the Parallel Architecture for linguistic structures. In addition, graphic structure (the layout of comics panels on a page), which is a key element of Cohn's representations, is not relevant to the present paper either. Finally, Cohn's (2013) application of visual narrative structure principles to verbal discourse consists of a comparison between sentences and phrases, on the one hand, and the panels of graphic structure. For instance, several sentences and phrases can exemplify prototypical narrative categories reflected in graphic structure. For example, "There once was an X..." is a prototypical Establisher, while "And they all lived happily ever after" is a prototypical Release. Again, these notions are not directly relevant to the current study.

Principles and concepts discussed above such as foregrounding, immediacy, and telicity provide a framework for the following research questions, which guide the present study:

1. How does narrative structure interact with the semantics of the verbs involved in the use of HP?

2. How does narrative structure interact with the semantics of the verbs involved in narrative exclusively in the present timeframe?

These questions are addressed through the analysis in $₫ 5$. Before that, the results of the corpus study are presented in $\$ 3$, and background information on the Parallel Architecture framework is presented in $\$ 4$. It is important to emphasize that the current study presents a novel approach to the exploration of the interface between semantics and pragmatics in being the only study that applies the Parallel Architecture to an analysis of verbal discourse.

\section{Corpus study}

\subsection{Method}

The corpus study was conducted using the Corpus del Español (CDE) (Davies 2002-) (corpusdelespanol.org), an online corpus consisting of more than 100 million words from more than 20,000 Spanish texts from the 1200 s to the 1900 . The corpus texts appear in four registers beginning in 1900, namely, spoken, fiction, newspaper, and academic. Only texts from the 20 th century section were searched because of the availability of the four registers, as well as to obtain the most modern usage. Such texts consist of over 20.5 million words, with approximately equal amounts of words per register. Examples from all four registers were used in the 
study. The spoken texts, which are relevant to make comparisons with studies that analyze conversational narratives, consist of transcribed interviews and therefore are conversational.

The corpus study was not meant to be exhaustive, nor does it need to be for the purposes of this study. The main goals of the corpus study were to obtain additional naturally-occurring data on the use of HP in the spoken register; to determine the frequency of the use of HP in a variety of authentic texts from different registers; and to get a better idea of the use of HP in written texts. Searches were conducted with the achievement verbs llegar 'arrive', decir 'say', and empezar 'begin', in the simple present (3rd person singular). These verbs appear relatively frequently in data from other studies (cf. Van Ess-Dykema 1984; Silva Corvalán 1983; Schiffrin 1981), and were chosen in order to have a representative verb from each of three semantic classes that are common for achievement verbs, namely, verbs of motion (llegar), verbs of saying (decir), and 'begin' verbs (empezar). The verbs llegar and decir in particular are quite common in conversational narrative. For instance, decir was the most frequently used achievement verb in Bonilla's (2011) study. Thus, while the corpus study is not indispensable to the analysis presented in $\$ 5$, it serves to provide supporting authentic data in the form of real-life examples of the use of HP.

A total of 1200 tokens were analyzed, 400 per verb. The determination whether a given simple present form was HP was made by hand. A form was judged as HP if it could be felicitously substituted with the preterite. The CDE makes available an extended context for each concordance item, so in cases when the concordance content was not enough to decide regarding HP, the extended context was used, and it proved to be an effective aid.

\subsection{Results and discussion}

The corpus study yielded an overall use of HP of $20 \%$. This is somewhat low compared to results for spoken narratives in other important studies, such as Silva Corvalán $(1983 ; 32.7 \%)$ and Schiffrin $(1981 ; 30 \%)$. This may be due to the predominance of written texts in the corpus and would support the traditional explanation that HP is more common in conversational narrative because its purpose is to make events more immediate and vivid, as well as Lubbers-Quesada's (2004) observation that writing tends to be a distancing task. Interestingly, Van EssDykema (1984), who conducted a study with two groups of native Spanish speakers, found that while $35 \%$ of speakers in one group (Mexican and Guatemalan students in an urban ESL class) exhibited use of HP, the level of use of HP in the second group (Honduran speakers telling personal narratives) was 19\%, almost exactly the same as in the present corpus study. 
As seen in Table (1), there is a surprisingly rare use of HP in oral texts in the corpus, which may be because these are interviews and not narratives per se. In written texts, the use of HP is quite low in news and academic sources, but relatively frequent in fiction (almost half of the examples within that register) in comparison to the three other registers (see sample sentences in (4-6) below).

Table 1. Examples of HP in CDE

Overall use of HP: $240 / 1200=20 \%$

a. Examples of HP in CDE with llegar 'arrive'

Number of examples of HP per register:

Oral: 11/10o examples

$11 \%$

Fiction: 46/100 examples

$46 \%$

News: 18/10o examples

$18 \%$

Academic: 5/100 examples

$5 \%$

Total: $80 / 400$

$20 \%$

HP

(Total examples for llega 'arrives': 2031)

b. Examples of HP in CDE with decir 'say'

Number of examples of HP per register:

Oral: $3 / 100$ examples

Fiction: 59/100 examples

$59 \%$

News: 4/100 examples

$4 \%$

Academic: 2/100 examples

$2 \%$

Total: $68 / 400$

$17 \%$

HP

(Total examples for dice 'says': 7794)

c. Examples of HP in CDE with empezar 'begin'

Number of examples of HP per register:

Oral: 19/104 examples

$18 \%$

Fiction: $37 / 100$ examples

$37 \%$

News: 17/100 examples

$17 \%$

Academic: 19/96 examples

$20 \%$

Total: 92/400

$23 \%$

HP

(Total examples for empieza 'begins': 987) 
It seems that many novels are narrated almost entirely in the present. From the illustrative sample concordances taken from the corpus presented below (4-6), it can be seen that examples from fiction (e.g. 4b, 5b, 6b) seem to indicate that large segments of a novel (or the entire novel) are being told in HP, with little or no alternation with the preterite. This seems to be the so-called continuous present tense typically found in (realist) novels and historical passages (Fludernik 1991). As also noted by Fludernik, another situation where the present is used exclusively in storytelling is what she calls the narrative present, in which all verbs in the plotline are in the present tense, with no tense alternation (similar to the RHP). Silva-Corvalán (1983) mentions spoken narratives (and provides an example) where the exclusive use of HP does not make the narration more vivid but simply reproduces the rules for the use of the present in the description of events in a novel, which are not necessarily the same as in speech. This could well be the continuous present.

In interviews and news HP is sometimes used when referring to or retelling events in a novel (examples below: Oral: 6a-40, News: 5c-5802). This seems to be what Fludernik (1991) refers to as the literary historical present, which is primarily found in recreations of oral storytelling (Chaucer's Tales, diaries, letters, biographies), but can also be found when retelling or referring to events in a novel. Some of the news articles in the corpus incorporate transcribed interviews, some of which include discussion of literary works, which may contribute to a slight increase of HP for that register. Notice also that in some corpus examples there are past dates (e.g. 4b-810, 5c-5764), and other verbs in the context appear in the preterite (e.g. $4 \mathrm{a}-83,6 \mathrm{~d}-926)$, both of which facilitated the determination whether HP was being used.

(4) Concordances with llega 'arrives'

a. Oral

Entonces el tipo llega y le abre la puerta esta mujer y le dice: “Tú eres el ... [Then this guy arrives and this woman opens the door for him and she tells him: "You are the...]

b. Fiction

Esa es la época cuando llega a Chile en 1933 el arquitecto Roberto Dávila de regreso de una estadía en el ...

[That is the time when architect Roberto Dávila arrives in Chile in 1933 returning from a stay in the ...]

c. News

Munich y Augsburgo, donde mantiene una relación con su prima Bäsle. 1778. Llega a París.

[Munich and Augsburg, where he has a relationship with his cousin Bäsle. 1778. He arrives in Paris.] 


\section{d. Academic}

... sucumbe a la ambición y llega hasta el asesinato. A lo largo de la obra, Macbeth ...

[... succumbs to ambition and arrives at the point of murder. All through the play, Macbeth ...]

(5) Concordances with dice 'says', 'tells'

a. Oral

Conocí poco a Pasternak - dice -. Sólo nos vimos tres o cuatro veces ...

[I did not know Pasternak well - he says -. We only saw each other three or four times ...]

b. Fiction

La vieja dice que no tiene un centavo ni para yerba; a mi hermano, entonces...

[The old woman says that she does not have a penny, not even for weed; to my brother, then ...]

c. News

... más tarde, el 9 de julio de 1778, Mozart le dice que "la señorita Guines no es una persona para ser compositor" ...

[... later, on July 9, 1778, Mozart tells him that "Mrs. Guines is not one to be a composer" ...]

... de Isaac a la fea "Luisa" da un giro positivo cuando ella le dice que sólo se casará con él si se fugan juntos ...

[... from Isaac to ugly "Luisa" it takes a positive turn when she tells him that she will marry him only if they elope ...]

d. Academic

Por ejemplo, en el Nuevo Testamento el discípulo Tomás le dice a Jesús:

“iMi Señor y mi Dios!"

[For example, in the New Testament Thomas the disciple tells Jesus: "iMy Lord and my God!"]

(6) Concordances with empieza 'begins', 'starts'

a. Oral

¿Viste que cuando les avisaron uno empieza a huir y huir ...?

[Did you see that when they let them know one of them starts to escape and escape ...?]

b. Fiction

El peregrinar empieza, como he dicho antes, hacia 1880.

[The pilgrimage begins, as I have said before, around 188o.] 
c. News

El segundo empieza a partir de su reconocimiento internacional en 1912, y termina en $1930 \ldots$

[The second one begins with its international recognition in 1912, and it ends in 1930 ...]

d. Academic

La destilación en Estados Unidos no empieza hasta comienzos del siglo XVIII.

[Distillation in the United States does not start until the early XVIII century.]

\section{The Parallel Architecture}

The Parallel Architecture (Jackendoff 2002, 2007, 2010a; Culicover \& Jackendoff 2005) (henceforth PA) is a framework for linguistic theory that consists of independent generative phonological, syntactic, and semantic components that interface with each other, as seen in Figure 1.

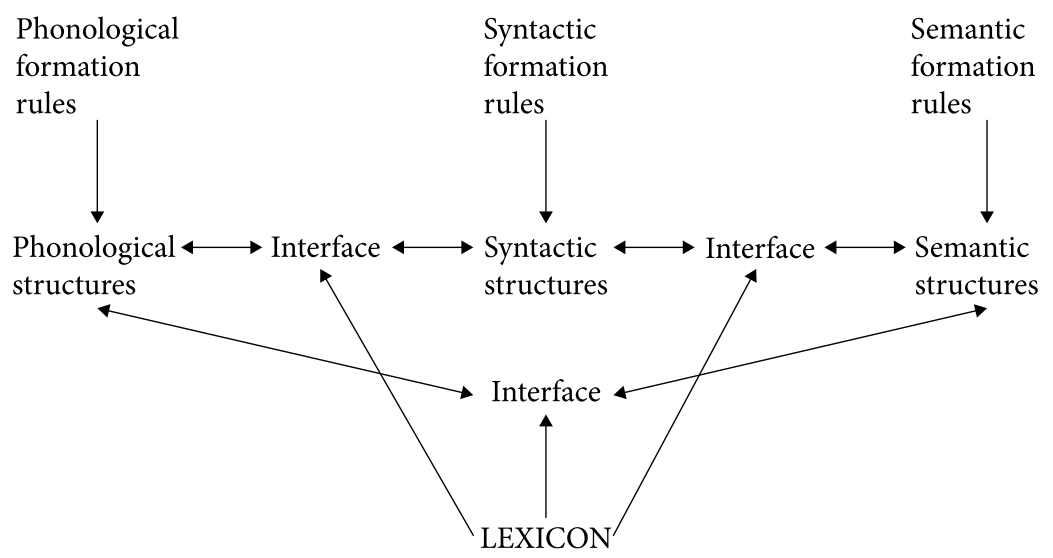

[Jackendoff 2007, Culicover \& Jackendoff 2005]

Figure 1. The Parallel Architecture

Each component consists of independent subcomponents called tiers, each with its own primitives and principles of combination. Just as the main components are linked via interface rules (Figure 1), the tiers are correlated with each other by interface rules as well (see Figure 3 below). Phonological structure (Figure 2) consists of at least prosodic, syllabic, segmental, and morphophono- 
logical tiers, while syntax is composed of a phrase structure (or constituent structure) tier (Figure 2, 3) and a grammatical function (GF) tier (Figure 3).

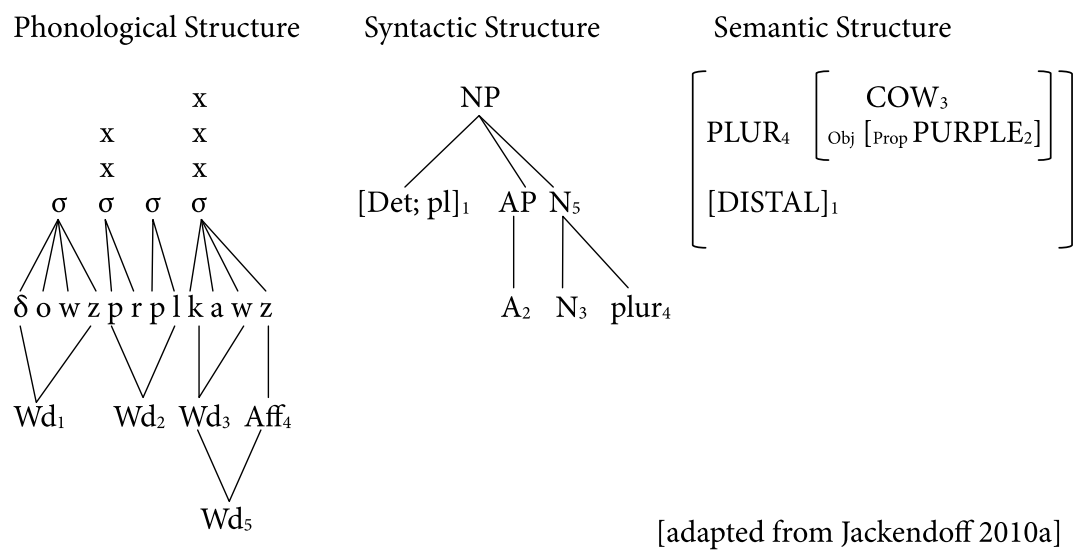

Figure 2.

John seems to like scotch

[SEEM ([LIKE $\left.\left.\left.\left(\mathrm{JOHN}_{3}, \mathrm{SCOTCH}_{4}\right)\right]_{2}\right)\right]_{1} \quad$ Conceptual Structure

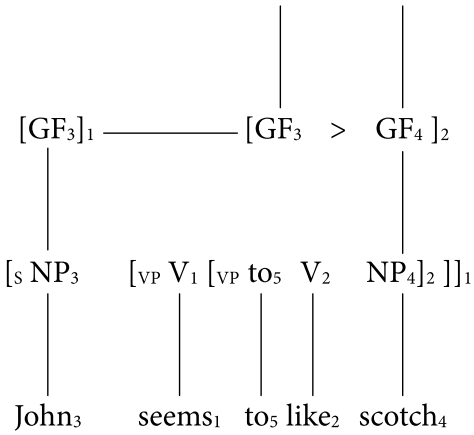

Grammatical Function Tier

Syntactic Structure

Phonological Structure

[Culicover \& Jackendoff 2005]

Figure 3.

Semantics (also called Conceptual Structure in PA terminology) consists of several tiers as well, including a descriptive tier (labeled CS, short for Conceptual Structure, and also called propositional structure), which is shown under the label "Semantic structure" in Figure 2, and also as the top tier in Figure 3; a referential tier, an information structure tier, and other possible tiers (see $\$_{5}$ ) pertaining to conversation, narrative, and discourse in general, all of which form part of pragmatics. In PA, semantics is seen as providing the part of conceptual structure of 
an utterance that is directly related to linguistic expression, while pragmatics provides the part that arises through heuristics, world knowledge, and understanding of the context (Jackendoff 2010a). However, there is no formal distinction of level in PA between semantics and pragmatics. Thus, semantics and pragmatics are intimately related, and this link is formalized in linguistic representations.

The representation of pragmatic tiers in the model developed in $\$ 5$ follows the standard PA notation, with the components of a tier, such as Topic (known information) and Focus (new information) simply placed next to each other, as in Figure 4, where the information structure tier is shown linked to CS. Figure 4 also shows the interaction between information structure and the prosodic tier from phonology. As Jackendoff (2002) observes, prosody plays a crucial role in the expression of information structure. This is reflected in $(4 b, c)$. In ( $4 b)$, a speaker can be seen as responding to the question "What did Bill read?" The word novel is boldfaced to show that it is a stressed word that provides new information, and thus is linked to Focus. In (4c), on the other hand, the speaker is replying to the question "Who read the novel?" and, accordingly, it is Bill that is stressed and is now the focus. These changes in linking between tiers are relevant to the discussion of the model in $\$ 5$, where alternate linkings between tiers account for differences and similarities in the interpretation of different types of verbs when HP occurs.

a. Phonology:

CS:

Information Structure:

b. CS:

Information Structure:

Prosodic Structure:

c. CS:

Information Structure:

Prosodic Structure:
Bill read the novel.
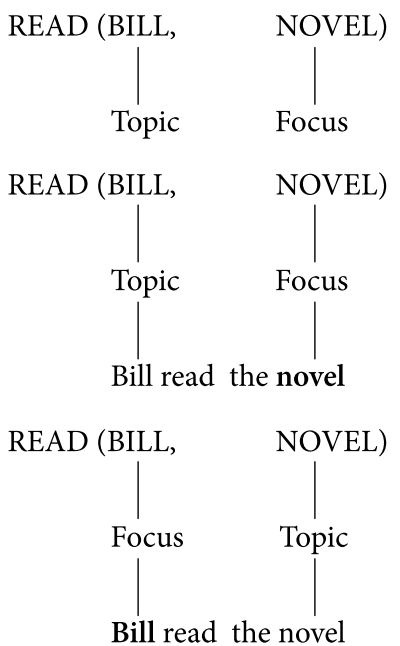

[adapted from Jackendoff 2002]

Figure 4 . 
Jackendoff (2010a) provides several justifications for why the PA may be preferable to other models. He begins by emphasizing the generative capacity of the semantic component (conceptual structure) in PA, and cites this as an advantage when compared to the Minimalist Program (Chomsky 1995) (and more generally mainstream generative grammar) and Cognitive Grammar (Langacker 1987), which represent extremes. In the Minimalist Program the combinatorial properties of semantics (and phonology) are derived from syntax, which means that there are no independent formation rules for the semantic component, and this puts the syntactic component under constant pressure for greater complexity to reflect the richness of semantic structure. On the other hand, in Cognitive Grammar all (or most) syntactic structure is derived from semantics, which eliminates or minimizes syntactic formation rules. According to Jackendoff, the PA strikes the proper balance between these two extremes.

A second crucial advantage cited by Jackendoff is that the PA extends naturally to the relation of language to other capacities such as visual perception. The relation between language and vision can be seen as yet another interface component, in this case linking semantic structure to the combinatorial structures responsible for visual understanding (which cannot be derived from syntax). Vision is just one example; the PA is applicable to all scales of mental organization.

Jackendoff (2013) provides a third justification for why PA should be preferred to other models. The PA is preferable to the Minimalist Program, for example, in that in the PA, competence (knowledge of linguistic structure) is put to work directly in performance (language processing), making the theory lend itself to a more direct relation between competence and performance than mainstream generative grammar does.

A final advantage is directly relevant to the current study. PA distinguishes itself from other influential theoretical frameworks in the incorporation of both semantic and pragmatic tiers. Neither the Minimalist Program nor HPSG (Pollard and Sag 1994), for example, organize linguistic structure in tiers; and while HPSG integrates pragmatics into linguistic representations, the Minimalist Program does not postulate a component devoted to pragmatics. The richness of tier structures in PA makes it ideal for use in a model, such as the one developed here, that connects semantics and discourse in a principled way.

In the next section, HP is analyzed utilizing the elements of PA outlined above, and a model based on this theoretical framework is proposed. 


\section{The Historical Present and the interaction between semantics and pragmatics}

\subsection{Narrative in the past}

As mentioned in $\$ 2$, this section is based in part on the corpus data gathered and results from Bonilla's (2011) studies. According to Bonilla (2011), tense shifting is rooted in the interaction between the inherent semantics of verbs, temporal marking, and the dynamics of the conversation. As reflected in our research questions, it is the first of these, the inherent semantics of verbs, that is central to the model proposed in Chart 1 below, which shows the links between the grammatical, semantic and narrative elements that are relevant to HP. According to Bonilla's (2011) results, activities and accomplishments rarely occur with HP as compared to achievements. On that basis, Chart 1 makes a comparison between achievements (llegar) in the preterite and HP. These in turn are compared to a state verb in the imperfect (estaba 'was') in order to show contrasts and similarities between states and achievements.

Note, for example, that in accordance with what was indicated in $\S 2$, in the preterite and HP columns (2, 3 respectively), the aspectual feature PERF (for telic verbs) is associated with the foreground (FORE), while in column 1 the aspectual feature IMP is linked to the background (BACK). It is important to stress that the discussion of how elements from one tier link to elements in other tiers (in this and the next section) forms part of the original contribution of the current model. This linking has not been suggested or proposed in Bonilla (2011), Mayberry (2011), or any other studies.

The verbs analyzed in Chart 1 appear in the third person (singular) based also on Bonilla's (2011) results, which show that third person forms outnumber firstand second-person forms in narratives. In addition, the preterite, imperfect, and especially HP tend to pattern with the third person.

The dotted lines in the HP column in Chart 1 indicate that an element on one tier (say, FORE on Tier 3) should typically be attached to an element on another tier (PAST on Tier 4) different than the one it is actually attached to (PRES on Tier 4). This visual device serves as an indicator that the use of HP, although more frequent than the preterite in some narratives (cf. Bonilla 2011), is a departure from prototypical usage. This alternate linking between tiers accounts for how a structure that is frequent (such as HP) can be marked. As Fleischman (1990) notes, in a narrative the preterite is the unmarked tense, so that a present tense alternating with the preterite can be considered foregrounded or marked. The alternate linking in Chart 1 could also be considered to reflect what goes on when the switching in tenses occurs anytime HP is used. For example, the 
dotted line in the HP column between Tiers 3 and 4 indicates that the speaker can return to the preterite to reestablish reference to the past, either as part of the regular switch between the preterite and HP, or as in the situation after an interruption described in $\$ 2$, where the speaker resumes with the preterite to reestablish the reference to the past. Recall from Figure 4 that alternate linkings were shown to occur between the information tier and the prosodic tier, depending on which argument is being focused. Thus, there is precedent in PA for this type of mechanism.

The link between PRES and IMM (Tiers 4,5 ) in the HP column indicates that the use of the present serves the pragmatic function of making an action that occurred in the past more immediate (and dramatic) to the listener/reader, thus helping to reduce the narrative distance implied by the preterite, and the past in general. Note in turn in Tiers 5 and 6 of the HP column that even though ${ }_{3} \mathrm{P}$ should prototypically be linked to DIST, it is actually linked to IMM. This, again, reflects the pragmatic function of HP to make events more immediate and vivid (cf. Bonilla 2011; Dunn 1998). Note that there are no dotted lines in columns 1 and 2, which indicates that there are no departures from the prototypical connections between tiers.

\begin{tabular}{|c|c|c|c|c|}
\hline & & 1 & 2 & 3 \\
\hline & & & Prototypical (preterite) & HP \\
\hline & & State & Achievement & Achievement \\
\hline & $\mathrm{Ph}:$ & estaba & llegó & llega \\
\hline 1 & CS: & {$\left[\begin{array}{ll}\mathrm{X}_{\mathrm{i}} & \mathrm{BE}\end{array}\right]$} & [X $\mathrm{X}_{\mathrm{i}}$ BECOME TO Z] & {$\left[\mathrm{X}_{\mathrm{i}}\right.$ BECOME TO Z] } \\
\hline 2 & GramAspS: & PERF IMP & PERF IMP & PERF IMP \\
\hline 3 & NarrS: & FORE BACK & FORE BACK & FORE BACK \\
\hline 4 & TimeRefS: & PAST-PRES-FUT & PAST-PRES-FUT & PÁST-PRES-FUT \\
\hline 5 & DistS: & DIST IMM & DIST IMM & DISTT IMM \\
\hline 6 & PersonS: & $1 \mathrm{P} 3 \mathrm{P}_{\mathrm{i}}$ & $1 \mathrm{P} \quad 3 \mathrm{P}_{\mathrm{i}}$ & $1 P \quad 3 P_{i}$ \\
\hline
\end{tabular}

Chart 1. Semantic/pragmatic tiers in narrative in the past

(Notation: $\mathrm{Ph}=$ Phonology; $\mathrm{CS}=$ Conceptual Structure; GramAspS = Grammatical Aspect Structure; NarrS = Narrative Structure; TimeRefS = Time Reference Structure;

Dist $\mathrm{S}=$ Distance Structure; PersonS $=$ Person Structure; DIST = Distant;

IMM = Immediate) 
Chart 1 shows that inherent lexical aspect (contained in the CS tier) is key, since it is the origin or anchor for the linking with the other tiers. Tiers $3-5$ are set in boldface to indicate that they belong specifically to narrative structure, which in turn is a part of discourse. (Tier 4 could alternatively be considered a syntactic tier for tense.) The location in the representation of Grammatical Aspect Structure (Tier 2), right next to CS, is important for two reasons. First, because it shows the close association between grammatical aspect and lexical semantic content, and, second, because it illustrates how GramAspS serves as an intermediary or bridge between the inherent semantics of CS and narrative structure.

The tiers shown in Chart 1 are the only ones that are directly relevant to HP. However, in accordance with PA principles, tiers can connect to other tiers in components not shown on the chart. For example, CS maps to the Grammatical Function (GF) tier (subject, objects) (see Figure 2 above) (cf. Culicover and Jackendoff 2005), the Referential tier (Jackendoff 2002) and Information Structure (Jackendoff 2002), which in turn can link with Prosodic Structure (also shown in 9), (cf. Culicover and Jackendoff 2005), one of the tiers of the phonological component. Other tiers related to narrative structure are conceivable. For instance, the elements involved in turn taking in conversation could be a part of an Interaction tier. This is fully compatible with PA, which allows for multiple connections among a wide array of structures.

As mentioned in the introduction, PA draws heavily from Conceptual Semantics, a mentalist theoretical framework, and as such it seeks to study how linguistic structures are represented in the mind. However, the tiers and connections between them are not necessarily represented in the mind as columns and rows as depicted in Chart 1 above (and Chart 2 below). They could well be organized in networks or other types of structures. Moreover, this model is not meant to capture everything that goes on in the speaker's (or listener's) mind when using HP, or in narrative exclusively in the present timeframe (next section). It accounts for aspects of the interaction between semantics and pragmatics.

The fact that GramAspS serves as an intermediary or bridge between the inherent semantics of CS and narrative structure is an indicator that the proposed tier structure model is not ad hoc or arbitrary; it is a well-motivated model, and not merely a representation, because it provides an explanation for how certain tiers pertaining to narrative structure interact both with conceptual structure and with each other, and why they do so.

In addition, recall from Figure 2 above that the notion of plurality can be expressed both as a syntactic feature ("pl" and "plur" in 2) and also as a semantic feature (PLUR). The same is the case for the features in Tier 4 in Chart 1 (PAST, PRES, FUT). An argument could be made that these features could well be represented as part of CS and not as a part of Time Reference Structure (Tier 4). 
However, time reference is a well-established notion in the study of discourse and narrative structure (cf. Dunn 1998; Bardovi-Harlig 1998; Bonilla 2011, and discussion in $\$ 2$ ), and therefore there is strong justification for representing it as a structural tier that is part of narrative structure. The same argument can be applied to the tiers containing FORE - BACK and IMM - DIST. This is part of the novel contribution of the present article to the field: conceiving these well-established elements in the analysis of discourse as formal tiers in narrative structure that perform a function when speakers interpret or produce verbs in discourse.

Furthermore, recall from $₫ 4$ that CS consists of several tiers, including the descriptive tier (Tier 1 above) and the referential tier. Semantic functions such as PLUR and PAST could well be represented as a part of CS, as in Figure 2 and also as in examples of CS from Jackendoff (2010b), which in addition contain features such as BOUNDED and UNBOUNDED. However, no matter how many of these features are incorporated into CS or how rich the CS representations are, no advantage would be gained since these features would still have to form part of the descriptive tier, not of narrative structure, and thus would not help establish a connection between CS and narrative structure, as Chart 1 does. In other words, the distinctions in narrative structure cannot be reflected in CS alone, which according to Jackendoff (2010a) is a strictly semantic tier and not a part of narrative structure. Tiers such as the one for time reference are needed to show the interaction between the semantics of the verb and the elements of narrative structure, as well as the relationship between the tiers of narrative structure themselves.

This in turn brings us to a justification for using charts such as 1 and 2. As noted above, the tiers and connections between them are not necessarily represented in the mind as columns and rows as depicted in Chart 1 . However, the charts do not present the information in that format merely to enhance organizational readability or to compare structures. The charts are meant to provide a plausible explanation, in a visual format, of how speakers interpret and produce this type of verbs in a conversational context when HP occurs.

\subsection{Narrative exclusively in the present timeframe (no use of HP)}

As noted in $\$ 2$, this section is based in part on data from Mayberry’s (2011) study. Even though HP is not directly related to the topic addressed in this section, the representations illustrated in Chart 2 below are quite similar to those in Chart 1 , and the same design principles from Chart 1 apply to Chart 2.

As noted above, according to Mayberry 2011, the use of the simple present and the present progressive in narrative within the present timeframe parallels the use of the preterite and imperfect in narrative in the past, respectively. This is reflected in Chart 2 below, where the connections between tier structures for 
different forms of the achievement verb llegar are illustrated. Columns 3 and 4 are boldfaced to make the separation between past and present tenses clearer. In turn, columns 2 and 3 have been italicized in order to make visually clearer the relationship between the preterite and the simple present, on the one hand, and the imperfect and present progressive, on the other. As can be seen in Chart 2, both the preterite and simple present (columns 2, 3), which have the function of moving the action forward, are linked to the foreground, while the imperfect and the present progressive (columns 1, 4) are linked to the background, each in their respective time frame.

\begin{tabular}{|c|c|c|c|c|c|}
\hline & & 1 & 2 & 3 & 4 \\
\hline & & Imperfect & Preterite & Simple present & $\begin{array}{l}\text { Present } \\
\text { progressive }\end{array}$ \\
\hline & $\mathrm{Ph}$ : & llegaba & llegó & llega & (está) llegando \\
\hline 1 & CS: & {$\left[\mathrm{X}_{\mathrm{i}}\right.$ BECOME TO Z] } & [X $X_{i}$ BECOME TOZ] & {$\left[X_{i}\right.$ BECOME TO Z] } & {$\left[\mathrm{X}_{\mathrm{i}}\right.$ BECOME TO $\left.\mathrm{Z}\right]$} \\
\hline 2 & GramAspS: & PERF IMP & PERF IMP & PERF IMP & PERF IMP \\
\hline 3 & NarrS: & FORE BACK & FORE $B A C K$ & FORE BACK & FORE BACK \\
\hline 4 & TimeRefS: & PAST-PRES-FUT & PAST-PRES-FUT & PAST-PRES-FUT & PAST-PRES-FUT \\
\hline 5 & DistS: & DIST IMM & DIST IMM & DIST IMM & DIST IMM \\
\hline 6 & PersonS: & $1 \mathrm{P} \quad 3 \mathrm{P}_{\mathrm{i}}$ & $1 P \quad 3 P_{i}$ & $1 P \quad 3 P_{i}$ & $1 \mathrm{P} 3 \mathrm{P}_{\mathrm{i}}$ \\
\hline
\end{tabular}

Chart 2. Semantic/pragmatic tiers in narrative in the present

The remaining links between tiers are the ones appropriate for each verb. Since this is the simple present and not HP, there are no departures from prototypical usage (column 3 ) and therefore no dotted lines.

As Mayberry (2011) notes, the inherent lexical system (Tier 1 in Chart 2) interacts with discourse principles to encode aspectual distinctions. The discourse constraints that occur in the context of synchronous narratives elicit the use of the simple present and the present progressive in a manner parallel to the preterite/ imperfect in the past. As a novelty of the current model, these "discourse principles" can be seen as structures in PA (Tiers 3-5 in Charts 1, 2); the "aspectual distinctions" are conveyed by the differences in linking (Tier 2); and "discourse constraints" are determined both by differences in linking and by the structures themselves (again, Tiers $3-5$ ). This is in accord with the philosophy behind PA, 
where traditional rules such as phrase structure (rewrite) rules Figure (5a) are expressed instead as structures ( $5 \mathrm{~b}$ and $\mathrm{c}$ ), and principles and constraints (such as interface rules) are expressed as linked and coindexed structures (Figure 3, 6).
a. $\mathrm{VP} \rightarrow \mathrm{V}-\mathrm{NP}$
b. $[\mathrm{vP} \mathrm{V}-\mathrm{NP}]$
c.

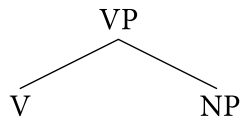
[adapted from Jackendoff 2010a]

Figure 5.

\begin{abstract}
Argument structure Grammatical function structure
$\left[\right.$ Agent $_{1}>$ Patient $\left._{2}\right] \leftrightarrow\left[\right.$ Subject $_{1}>$ Object $\left._{2}\right]$
\end{abstract}

[adapted from Culicover \& Jackendoff 2005]

Figure 6. Interface rule

The term "architecture" in the name of the framework is not used lightly. PA is based crucially on (linguistic) structures.

As noted above, Charts 1 and 2 share the same design principles. Notice, additionally, that their format and structural components are identical. It is noteworthy that two different phenomena - HP and narrative exclusively in the present timeframe - can be explained with the use of exactly the same type of representation. This suggests that, by unifying two distinct though related phenomena into a single explanation, the proposed model has a high degree of explanatory power. As explained above, the model instantiated in Charts 1 and 2 helps explain how speakers interpret and produce this type of verbs in a conversational context.

Finally, it is worth noting that semantic-pragmatic structure is assumed to be universal. As Van Ess-Dykema (1984) notes, the study of narratives has contributed to the goal of determining narrative and pragmatic universals. In a similar vein, the cross-linguistic evidence gathered in Silva-Corvalán's (1983) study suggests that a universal characterization of the discourse properties of temporal and aspectual elements in natural language may eventually be developed. Jackendoff (2002) speaks of a cognitive structure that is associated with narrative. $\mathrm{He}$ compares non-narrative conversations at dinner parties with a typical (conversational) narrative, observing that the random walk from topic to topic in the former is unacceptable for narrative, which is structured in a systematic way. This cognitive structure that narrative gives rise to is presumably universal. It stands to 
reason that the model developed here may be capturing at least part of the instantiation of a universal structure for narrative.

The present model is original in that it instantiates discourse principles and constraints as structures in a way that has not been done before. As noted above, it may well be that tier structures such as the ones illustrated in Charts 1 and 2 help speakers both interpret and produce verbs in discourse, and thus may be capturing a universal phenomenon.

\section{Conclusion}

This study has shown how an original model based on a recognized theoretical framework can be used effectively to explore the implications of HP for semantic and pragmatic structure in Spanish. The paper makes a major contribution to semantics and pragmatics by presenting an innovative model that extends Parallel Architecture principles to discourse, thus accounting in a more systematic way for the interaction between the inherent semantics of verbs and discourse principles and constraints. The fact that the representations in Charts 1 and 2 are so similar suggests that the model is an effective tool that serves to unify the explanation of distinct (though related) phenomena at the interface between semantics and pragmatics. Future studies could explore the application of the model to other types of tense switches in narrative, such as the shift from the past to the present progressive (labeled "HP progressive"), as well as to other possible tiers of narrative structure and discourse in general. Since semantic-pragmatic structure is assumed to be universal, future research could explore the application of this analysis to other languages, as well as to studies on second language acquisition. For example, the model may contribute to a better understanding or formulation of the Discourse Hypothesis, which holds that narrative structure determines the distribution of interlanguage verbal morphology, and learners use verbal morphology to distinguish foreground from background in narratives (cf. Hopper 1979; Bardovi-Harlig 1998).

\section{References}

Bardovi-Harlig, Kathleen. 1998. "Narrative Structure and Lexical Aspect: Conspiring Factors in Second Language Acquisition of Tense-Aspect Morphology." Studies in Second Language Acquisition 20: 451-508. https://doi.org/10.1017/S0272263198004021

Bonilla, Carrie. 2011. “The Conversational Historical Present in Oral Spanish Narratives."

Hispania 94: 429-442.

Chomsky, Noam. 1995. The Minimalist Program. Cambridge, Mass.: MIT Press. 
Cohn, Neil. 2013. "Visual Narrative Structure." Cognitive Science 34: 413-452. https://doi.org/10.1111/cogs.12016

Cohn, Neil. 2014a. "Narrative Conjunction's Junction Function: A Theoretical Model of "Additive" Inference in Visual Narratives." In Proceedings of the 36 th Annual Conference of the Cognitive Science Society, ed. by P. Bello, M. Guarini, M. McShane, and B. Scassellati, 2050-2055. Austin, TX: Cognitive Science Society.

Cohn, Neil. 2014b. "The Architecture of Visual Narrative Comprehension: The Interaction of Narrative Structure and Page Layout in Understanding Comics." Frontiers in Psychology 5: 1-9. https://doi.org/10.3389/fpsyg.2014.00680

Culicover, Peter, and Ray Jackendoff. 2005. Simpler Syntax. Oxford: Oxford University Press. https://doi.org/10.1093/acprof:0so/9780199271092.001.0001

Davies, Mark. 2002. Corpus del Español. www.corpusdelespanol.org

Dunn, W.E. 1998. "The Effect of Inherent Lexical Aspect and Grammatical Person on TenseSwitching in Oral Narratives." In Annual Meeting of the American Association for Applied Linguistics. Seattle: WA. Address.

Dyvik, Margrete. 2004. "El presente histórico en el español de América: Un análisis de la lengua hablada.” Español Actual: Revista de Español Vivo 81: 69-83.

Fleischman, Suzanne. 1990. Tense and Narrativity: From Medieval Performance to Modern Fiction. Texas Linguistics Series. Austin: University of Texas Press.

Fludernik, Monika. 1991. “The Historical Present Tense Yet Again: Tense Switching and Narrative Dynamics in Oral and Quasi-Oral Storytelling." Text 11: 365-398. https://doi.org/10.1515/text.1.1991.11.3.365

Hopper, Paul. 1979. “Aspect and Foregrounding in Discourse." In Syntax and Semantics:Discourse and Syntax, ed. by Talmy Givon, 213-241. New York: Academic.

Hopper, Paul, and Sandra Thompson. 1980. "Transitivity in Grammar and Discourse." Language 56: 251-99. https://doi.org/10.1353/lan.1980.0017

Jackendoff, Ray. 1990. Semantic Structures. Cambridge, Mass.: MIT Press.

Jackendoff, Ray. 2002. Foundations of Language: Brain, Meaning, Grammar, Evolution. Oxford: Oxford University Press. https://doi.org/10.1093/acprof:0so/9780198270126.001.0001

Jackendoff, Ray. 2007. Language, Consciousness, Culture: Essays on Mental Structure. Cambridge, MA: MIT Press.

Jackendoff, Ray. 2010a. Meaning and the Lexicon. Oxford: Oxford University Press.

Jackendoff, Ray. 2010b. "Parts and Boundaries." In Meaning and the Lexicon, 138-173. Oxford: Oxford University Press.

Jackendoff, Ray. 2013. “A Parallel Architecture Model of Language Processing.” In The Oxford Handbook of Cognitive Neuroscience, Volume 1: Core Topics (online), ed. by

Kevin N. Ochsner and Stephen Kosslyn. https://doi.org/10.1093/oxfordhb/9780199988693.013.0028, 22 pages. Oxford: Oxford University Press.

Labov, William. 1972. “The Transformation of Experience in Narrative Syntax.” In Language in the Inner City, 354-396. Philadelphia: University of Pennsylvania Press.

Langacker, Ronald. 1987. Foundations of Cognitive Grammar. Vol. i, Stanford, CA: Stanford University Press.

Lubbers-Quesada, Margaret. 2004. "Present and Imperfect for Past Description in Spanish Narratives." In Language, Culture, and Mind, ed by Michel Achard and Suzanne Kemmer, 329-344. Stanford: CSLI. 
MacWhinney, Brian. 200o. The CHILDES (Child Language Data Exchange System) Project: Tools for Analyzing Talk. Web.

Marcos Marín, Francisco. 1992. Corpus oral de referencia de la lengua española contemporánea. Web.

Mayberry, María. 2011. "Synchronous Narratives in Spanish: The Simple Present/Present Progressive Aspectual Contrast.” Hispania 94: 462-482.

Pollard, Carl, and Ivan Sag. 1994. Head-Driven Phrase Structure Grammar. Chicago: University of Chicago Press.

Schiffrin, Deborah. 1981. “Tense Variation in Narrative." Language 57: 45-62. https://doi.org/10.1353/lan.1981.0011

Sebastián, Eugenia, and Dan Slobin. 1994. "Development of Linguistic Forms: Spanish.” In Relating Events in Narrative: A Crosslinguistic Developmental Study, ed. by Ruth Berman and Dan Slobin, 239-284. New Jersey: Lawrence Erlbaum.

Silva-Corvalán, Carmen. 1983. "Tense and Aspect in Oral Spanish Narrative: Context and Meaning." Language 59: 760-780. https://doi.org/10.2307/413372

SPLLOC. 2009. Spanish Learner Language Oral Corpora: Linguistic Development in L2 Spanish. Web.

Van Ess-Dykema, Carol. 1984. The Historical Present in Oral Spanish Narratives. Washington, D.C.: Georgetown University Press.

Wolfson, Nessa. 1979. “The Conversational Historical Present Alternation.” Language 55: 168-182. https://doi.org/10.2307/412521

Wolfson, Nessa. 1982. CHP: The Conversational Historical Present in American English

Narrative. Dordrecht: Foris. https://doi.org/10.1515/9783110851694

\section{Address for correspondence}

\section{Carlos Benavides}

Department of Foreign Literature and Languages

University of Massachusetts Dartmouth

285 Old Westport Road

Dartmouth, MA 02747

USA

cbenavides@umassd.edu

\section{Biographical notes}

Carlos Benavides is Associate Professor of Spanish/Linguistics and Chair of the Department of Foreign Literature and Languages at the University of Massachusetts Dartmouth. He received his Ph.D. in Linguistics from the University of Iowa. His publications have appeared in prestigious journals such as Hispania and Foreign Language Annals, and he published a book on the semantics of Spanish word formation. His research interests include Hispanic linguistics, semantics, morphology, the use of linguistic corpora for linguistic analysis, the relationship between semantics and pragmatics, and language processing for second language acquisition. 
